\title{
REBECA CARRIÓN CACHOT, LA PRIMERA ARQUEÓLOGAY LA PRIMERA MUJER EN ASUMIR LA CÁTEDRA EN LA UNIVERSIDAD
}

\author{
EFRAín NúÑEz HuALLPAYUNCA \\ UNIVERSIDAD NACIOANL MAYOR DE SAN MARCOS \\ eslani_24@hotmail.com
}

\section{RESUMEN}

Sobre la arqueología en el Perú, si bien es cierto es importante conocer y divulgar los trabajos de campo que los arqueólogos realizan de nuestro pasado prehispánico, también lo es conocer la vida y obra de esos arqueólogos y arqueólogas que han trabajado en nuestro país, pero no solo de los ya conocidos, sino también de aquellos que hemos olvidado o no conocíamos. Bajo esa premisa, el objetivo del presente ensayo es conocer un poco sobre la vida académica de la Dra. Rebeca Carrión Cachot (1901-1960), notable sanmarquina que tuvo que vivir y enfrentar una época en la que las mujeres todavía luchaban por la emancipación de su género. Para esto, nos basaremos en la poca documentación que pudimos hallar en los archivos para mostrar, entre otras cosas, que la doctora Carrión es la primera mujer en asumir una cátedra en la universidad y la primera arqueóloga del Perú.

Palabras claves: Instituto de Arqueología, Plan de Estudios, cátedras, catedráticos, Rebeca Carrión Cachot

\section{Abstract}

On the archaeology in Peru, though it is true it is important to know and to spread the fieldworks that the archeologists realize of our pre-Hispanic past, also it it is know the life and work of these archeologists and arqueólogas that have been employed at our country, but not only of the already known ones, but also of those that we have forgotten or we did not know. Under this premise, the aim of the present test is to know a bit on the academic life of the Dra. Rebeca Carrión Cachot (1901-1960), notable sanmarquina that had to live and face an epoch in which the women still were fighting for the emancipation of his kind. For this, we will base in small documentation that we could find in the files to show, among other things, that the doctor Carrión is the first woman in assuming a chair in the university and the first arqueóloga of Peru.

Keywords: Institute of Archaeology, Study plan, chairs, professors, Rebeca Carrión Cachot 


\section{INTRODUCCIÓN}

En la historia institucional de una entidad, como la universidad, las escuelas académico-profesionales o una Facultad, los catedráticos son la columna vertebral, ellos le dan un espíritu especial a la institución que luego es reflejado en los alumnos cuando egresan y se desenvuelven en su ejercicio profesional, por eso, el objetivo de este ensayo es resaltar la figura de una de las catedráticas de la Escuela Académico Profesional de Arqueología de la Universidad de San Marcos, entonces llamado Instituto en la Facultad de Letras.

El ensayo abordará la vida académica de la Dra. Rebeca Carrión Cachot en la Universidad de San Marcos desde su época de estudiante hasta su retiro docente en 1956, tomamos como referencia esa fecha porque a partir de allí no hemos encontrado en los documentos la presencia de la doctora en la universidad ${ }^{1}$. Nueva documentación y acuciosos investigadores podrían dar y encontrar nueva información que ampliarían este trabajo que no pretende ser definitivo y que solo intenta rescatar y revalorar la figura de una ilustre sanmarquina.

El presente ensayo también es un breve aporte para futuros trabajos sobre la historia de la actual Escuela Académico-Profesional de Arqueología de la Universidad de San Marcos. Y es que conocer el pasado institucional de nuestras Escuelas, Facultades, Centros Federados y/o Universidad, genera identidad en los estudiantes y docentes que la integran, fortaleciendo así nuestra autoestima institucional.

\section{Contexto Universitario}

Rebeca Carrión ingresa a la universidad en una época donde los vientos de la Reforma Universitaria, provenientes de la universidad de Córdova-Argentina, estaban por llegar a las aulas de San Marcos. El Rector de entonces era el Dr. Javier Prado y Ugarteche, y el Dr. Alejandro Deustua era del Decano de la Facultad de Letras. Integraban el cuerpo docente de la Facultad los Dres. Adolfo Villagarcía, Antonio Flores, Manuel B. Pérez, Carlos Wiesse, Mariano H. Cornejo, Alejandrino Maguiña, Constantino Salazar, Luis Miró Quesada, Felipe Barreda y Laos, Óscar Miró Quesada, Pedro Yrigoyen, José de la Riva Agüero, Víctor Andrés Belaunde, Horacio H. Urteaga, José Gálvez y Juan B. Lavalle.

Durante las primeras décadas del siglo XX vemos el ingreso de las clases medias al ambiente universitario. Y será precisamente este nuevo grupo social que iniciaría la Reforma Universitaria en 1919, y que traería como consecuencia, entre otras, la salida de tres profesores de la Facultad de Letras: Antonio Flores, Manuel B. Pérez y Constantino Salazar.

Es en ese ambiente reformista que Rebeca Carrión pasaría sus primeros años de estudiante en la Facultad de Letras, pero no solo ella, también algunos de sus hermanos (Raquel y Carlos).

\section{La ÉPOCA de Estudiante UNIVERSITARIA}

Durante sus años como estudiante en la Universidad de San Marcos, Rebeca Carrión tuvo algunas dificultades, principalmente las de carácter económico. Hija de don Pedro José Carrión, coronel del ejército peruano fallecido en 1916, e Isabel Cachot, concertista y compositora, nuestra futura arqueóloga se matricularía en la Facultad de Letras en 1917.

1. Para realizar este ensayo tomamos como principal fuente de información algunos documentos del Archivo Histórico de San Marcos, pero al estar este en un proceso de inventario, no nos fue posible colocar en las referencias la ubicación exacta de los documentos porque estaban sin clasificar, lo único que podemos hacer es colocar en la parte final de la bibliográfica los años revisados. 
No tenemos suficiente documentación como para conocer algo más de la etapa universitaria de la Dra. Rebeca Carrión, pero con la información encontrada podemos al menos reconstruir un poco sobre su paso en la Facultad de Letras y los difíciles momentos que tuvo que pasar en aquel entonces. Por ejemplo, por referencia de Luis Alberto Sánchez sabemos lo siguiente sobre la presencia de las mujeres en la Universidad:

Yo recordaba los días de estudiante: de 109 alumnos del segundo año de Letras solo 3 eran mujeres: Rebeca Carrión Cachot, que llegó a ser directora del museo de Arqueología; Herlinda Cabrera Casas, pedagoga natural de Cañete, y Ana Luz Pérez Treviño muy estirada e impasible, hija del líder radical Benjamín Pérez Treviño, lugarteniente de Gonzales Prada en la Unión Nacional (1983: 78).

En abril de 1917, y en una de las sesiones de la Facultad de Letras, el secretario dio cuenta de dos solicitudes, una de don Gustavo Ramírez Villasante y otra de Rebeca Carrión Cachot para que se les exonerara el pago de los derechos de matrícula en la Facultad de Letras, fundándose ambos en su extrema pobreza conforme lo acreditan sus certificados respectivos. La Junta acordó la exoneración.

En julio de 1918, durante el segundo año de Facultad, y tras el fin del primer semestre lectivo, tres alumnos estuvieron sentados en una de las bancas del Patio de los Naranjos: Luis Alberto Sánchez, Rebeca Carrión Cachot y Julio Chiriboga, siendo este último quien "lanzaba miradas de carnero ahogado a Rebeca" (Sánchez 1969: I, 232).

En noviembre de ese mismo año se acordó aprobar la solicitud de doña Isabel Cachot, viuda de Carrión, para que se le exonerara a su hija Rebeca, alumna de la Facultad, de los derechos de examen. Similar situación ocurrió años después (XI-1923), en esta ocasión la Junta de catedráticos acordó aprobar la solicitud de doña Rebeca Carrión sobre la concesión del grado de Bachiller y la exoneración de los derechos correspondientes. Posiblemente los problemas económicos de la familia Carrión hayan sido los que la obligaran a posponer sus matrículas y obtención de grados académicos.

El 8 de abril de 1924 el Decano hizo presente que había varias becas de la fundación "Javier Prado" para ser concedidas, y propuso para una de las becas a la Bachiller Rebeca Carrión, alumna distinguida de la Facultad que estaba solicitando dicha beca para matricularse en el $3^{\circ}$ año.

Los hermanos de Rebeca Carrión también fueron beneficiados, por ejemplo, el 23 de abril se dio cuenta de los expedientes de los alumnos Carlos Carrión Cachot y Edmundo Espinoza, alumnos del $1^{\circ}$ año; don Ernesto Anaya y José C. Llosa, alumnos del $2^{\circ}$ año; y don José Jiménez Borja, alumno del $3^{\circ}$ año sobre concesión de becas. En este caso se aprobó conceder las becas previo estudio de las condiciones económicas de los postulantes.

Años después (30-IV-1927), la Junta de profesores acordó que las 4 becas creadas por la Universidad para los alumnos de la Facultad de Letras fueran para los siguientes alumnos: $1^{\circ}$ año: Pedro García Salas; $2^{\circ}$ año: don Ramiro Pérez Reinoso; $3^{\circ}$ año: doña Raquel Carrión Cachot; y $4^{\circ}$ año: Hugo Otero. Ese mismo día también se acordó ratificar por el presente año las becas "Javier Prado" adjudicadas el año anterior a los alumnos don Isaac Molero y don Carlos Carrión Cachot, estos últimos habían recibido la beca Javier Prado en 1926.

Por otra parte, la Facultad declaró expedito para optar el grado de Bachiller en Letras al estudiante Estuardo Núñez (13-IX-1930). Mientras tanto, por esos años, y como una consecuencia de la caída de don Augusto B. Leguía, entonces presidente del Perú, por el Comandante Luis Miguel Sánchez Cerro, ocurrió que el 30 de setiembre de 1930, el Dr. Julio C. Tello es destituido de la dirección del Museo de 
Arqueología Peruana que él había fundado. En su reemplazo se nombró al Dr. Luis E. Valcárcel. En solidaridad al Dr. Tello, estuvieron Rebeca Carrión y los señores Toribio Mejía Xespe, Alejandro Gonzales, Cristóbal Chessman, Horacio Tello Macavilca y Eugenio Yakowleff.

La Facultad de Letras sesionó el 20 de marzo de 1931 para la toma de posesión del Decanato por parte del Dr. José Gálvez (1931-1935), pero ni bien asumió el Decanato pidió licencia por algún tiempo hasta que terminase su función pública, pues en ese momento ocupaba la cartera de Justicia e Instrucción en la Junta de Gobierno presidida por el señor David Samanez Ocampo. La Facultad le concedió la licencia y nombran en su reemplazo al sub decano Alberto Ureta para dirigir la Facultad.

En aquella sesión se declaró expedita para el grado de Doctor a Rebeca Carrión Cachot. En la sustentación presentó la tesis titulada La indumentaria en la antigua Cultura Paracas, logrando el doctorado en Historia y Letras por “aclamación”.

\section{El INICIO de la Docencia Universitaria}

En la sesión del 21 diciembre de 1931, y bajo la presidencia del sub decano Alberto Ureta, se dio cuenta de diversas comunicaciones de los señores Richard Westerman, H. Money, Víctor E. Vivar, Mario Alzamora Valdez, Alfonso Villanueva Pinilla, Cipriano Angles, Gonzalo Bravo Mejía y la señorita Rebeca Carrión Cachot en la que se ofrecían para dictar cursos libres en la Facultad de Letras. Los doctores Julio C. Tello, Carlos Velásquez y Enrique Barbosa opinaron porque se exigiera a los postulantes a las cátedras libres ciertas condiciones que acreditasen su competencia y que la autorización para dictar esos cursos fuera puesta previamente en conocimiento de la Facultad. La Delegación estudiantil apoyó este pedido solicitando que los profesores de los cursos libres presentaran anticipadamente el programa del curso que pretendían dictar.

De esta manera, la Facultad autorizó el funcionamiento de las siguientes cátedra libres:

Arte Peruano Pre-colombino: Señorita Rebeca Carrión Cachot

Historia de la Educación en Alemania: Dr. Richard Westerman

Historia de la Educación en Inglaterra: Dr. Herbert Money

Reforma de la Escuela Primaria conforme a los principios del método Decroly: Dr. Víctor E. Vivar.

Historia de las Ciencias: señor Mario Alzamora Valdez

Historia de las Religiones: Dr. Alfonso Villanueva P.

Estadística Aplicada a la Educación: Dr. Cipriano Angles.

Principios de la Educación: Dr. Gonzalo Bravo Mejía.

Nótese que en la relación anterior se consigna a todos los profesores con su grado de doctor y a Rebeca Carrión como señorita a pesar que ya había obtenido su grado de doctor meses atrás.

Rebeca Carrión dictaría entonces la cátedra de Arte Pre-colombino en 1931, y con esto se convierte en la primera mujer en dictar una cátedra universitaria. Por ahora no hallamos documentos o información de alguna mujer que haya asumido una cátedra anterior a esa fecha.

Años después la Facultad volvió a sesionar (09-IX-1935), y se procedió a la provisión de algunas de las siguientes cátedras interinas: 
En Historia del Arte Peruano la votación fue así: Juan Manuel Peña Prado 4 votos contra 3 votos para Rebeca Carrión Cachot.

Psicología, catedrático interino al Dr. Adolfo Villanueva Pinillos.

Historia del Perú (segundo Curso) a José Valega como catedrático interino.

Sociología a Roberto Mac Lean por 3 votos contra 3 de Alberto Ballón, se decidió por Mac Lean.

Historia de la Cultura Moderna a César Patrón con 6 votos contra Raúl Ferrero Rebagliati.

Metafísica (curso doctoral) a Enrique Barboza con 5 votos.

Historia de la Literatura Castellana al Dr. Aurelio Miró Quesada con 6 votos.

Historia de la Literatura Moderna a Manuel Beltroy con 6 votos.

Literatura Americana y del Perú a Manuel Beltroy con 6 votos

Filósofos Contemporáneos a Julio Chiriboga con 4 votos contra 3 de Arguelles.

La sesión de la provisión de las cátedras interinas se suspendió para otra fecha. El 11 de setiembre se reabrió nuevamente la sesión y estuvo presidida por el Decano Horacio Urteaga. El Dr. Julio C. Tello pidió que constaran en el acta, como fundamento escrito de su oposición a la elección de los catedráticos Interinos, el siguiente documento:

Señor Decano: Creo cumplir un deber para con la Universidad, en mi condición de Profesor y miembro del Consejo Directivo de la Facultad de Letras, presentar a la consideración de la Junta de Catedráticos los fundamentos de mi opinión adversa al procedimiento empleado en la sesión de ayer para la elección de catedráticos Interinos.

En mi concepto, el procedimiento seguido en dicha elección no se ajusta a las prescripciones de la ley, ni a las aclaraciones de esta, hechas por el Rectorado, en el oficio dirigido a la Facultad con fecha 4 de setiembre.

El Rector en dicho oficio aclara y precisa el espíritu y propósito de la ley para el caso particular de la elección de catedráticos; pone en relieve el carácter legal y educacional del procedimiento a seguir; garantiza y reviste de seriedad el acto más trascendental de la vida universitaria, cual es, el de la investigación de su docencia.

Dicho documento es a la vez un Reglamento y un mandato, desde que emana de la primera autoridad universitaria, y su texto está basado en las prescripciones de la ley y en los principios que rigen la administración de universidades en general.

En la nota del Rector se determinan tres actos claramente definidos en el procedimiento de la elección: uno que antecede a este; otro relacionado con la elección misma, y el último, consecutivo a la elección. El primero se relaciona con las pruebas y testimonios que acreditan la eficiencia física, moral y docente del candidato, el segundo con el mecanismo de la elección; y el tercero, con la formación del expediente o credencial de cada candidato elegido, que es a la vez la única prueba testimonial de su eficiencia.

He aquí los preceptos o reglas a las que se sujeta conforme a la ley una elección de catedráticos Interinos: 
La puntuación de certificados, diplomas y otros documentos que sirvan para formarse criterio acerca de la edad y capacidad física, moral y docente del candidato.

La ratificación de la moral del candidato mediante votación secreta antes de la elección.

La presentación previa a la elección, del título académico o del diploma de Doctor del candidato.

La presentación igualmente antelada del título, o de los títulos emanados de otras universidades invocados por el candidato, sobre los cuales debe pronunciarse previamente el Consejo Directivo, y merecer así mismo, la aprobación del Consejo Universitario antes de producirse la elección.

La elección por dos tercios de los votos cuando se trate de candidatos no doctorados y egresados de la Facultad con éxito notable en sus estudios.

Por último, la obligación de la Facultad de elevar al Consejo Universitario todos los documentos relacionados con el proceso de la elección de cada candidato.

El Rector hace en su oficio un llamado a las autoridades Facultativas encargadas de la elección de catedráticos, en estos términos que merecen tomarse en muy seria consideración, por lo mismo que se invocan los elevados intereses de la futura Universidad:

El momento trascendental que vivimos exige imperativamente la observación fiel de preceptos destinados a mantener el prestigio ante el alumnado y la opinión culta del país; y ninguna forma más ejemplarizadora y que revele la acción educacional de la Universidad, sin duda, que el acto que se ha confiado a su autonomía de la designación de sus propias autoridades.

La elección de catedráticos interinos, como yo lo manifesté en la sesión de ayer, no se ciñe al procedimiento señalado por la ley y por el Rector, se procedió a la elección de catedráticos sin tener a la vista los documentos que acrediten la personalidad moral, profesional y docente del candidato. No hubo sesión previa del Consejo Directivo para la calificación de candidatos que no tenían títulos emanados de la Facultad. No se realizó la votación secreta previa que señala la ley sobre la moral de los postulantes. No ha sido observado en suma las prescripciones que tienden a asegurar la legalidad de la elección.

La ley al confiar a la Junta de catedráticos la elección de su personal docente ha investido a esta de una lata responsabilidad. La Universidad existe para servir los intereses educacionales de la juventud; es la fuerza educacional más importante del país y sus actos deben ajustarse a normas de la más severa autoridad. Debe en mi concepto, primar en sus actos los principios morales y legales que puedan ser un ejemplo para la juventud y un exponente del alto espíritu educacional de la Universidad.

Considero que no debió la Junta, por ahora, elegir catedráticos interinos que no reunieran el requisito del Doctorado.

No debió otorgarse el privilegio de acumulación de cátedras en un mismo candidato.

Es contrario a todo procedimiento de elección o de apreciación de los postulantes, realizar, como se ha hecho, primero la elección, y después solicitar del elegido las pruebas de su eficiencia que hasta ahora no han sido presentadas, a excepción de una corta auto-biografía, enviada por algunos de ellos.

Por último, por lo mismo que se trataba se habilitar profesores universitarios mediante una elección, era indispensable solicitar previamente el programa de la cátedra vacante.

Son los elegidos personas honorables, y probablemente capacitadas en las diversas ramas del conocimiento humano; pero en éste caso especial, la Universidad demandaba a favor de la enseñanza, el 
concurso de personas capacitadas en determinadas materias o cátedras. Sociología Peruana, Historia Colonial, Arte Peruano, son cátedras que requieren conocimientos muy vastos y especializados; son ciencias y artes que aún no se han sistematizado debidamente. Por tanto, es muy aventurado confiar esta clase de cátedras a personas que no han revelado en alguna forma su competencia en dichas materias.

Consiente de la transcendencia que este acto de la Junta de profesores va a tener en la vida universitaria, pido que mis opiniones aquí vertidas consten en el acta de la sesión de la Facultad, y sea elevado este documento al Consejo Universitario.

Lima 11 setiembre 1935

Julio C. Tello

Profesor de Arqueología Americana y del Perú

Como vemos, el Dr. Tello no estaba de acuerdo con algunas de las elecciones de los catedráticos interinos, y al referirse al curso de Historia del Arte Peruano, no hacía otra cosa que apoyar a la Dra. Rebeca Carrión, que no había sido elegida. El Decano manifestó entonces que las elecciones se habían verificado de acuerdo con la ley y las indicaciones del Rectorado. Agregó que no habiendo postulantes para las cátedras, sino en casos excepcionales, no cabía la clasificación previa de las condiciones físicas y morales de los presuntos catedráticos ni la presentación de diplomas o títulos que acreditasen sus capacidades docentes. Finalizó diciendo que las prescripciones del Rectorado se cumplían como habían sido prescritos en el oficio recibido acompañado con el acta de la elección los títulos y diplomas del elegido.

El Dr. Salinas Cossío expuso que debería quedar constancia de que en el acta de la elección se había hecho conjuntamente la calificación de la moralidad de los candidatos. Agregó que la calificación previa de la moralidad de los postulantes se usaba en los concursos donde la presentación de los candidatos hacía posible dicha calificación, pero que no era posible en el caso presente, donde no los había, importando la elección verificada, la calificación conjunta de la capacidad y de la moralidad del elegido.

Rebeca Carrión se presentó al concurso convocado por la Facultad de Letras para la provisión de la cátedra de Historia del Arte Peruano, y estuvo compitiendo con el Dr. Peña Prado. El resultado de la votación había sido un empate que al final el Decano Horacio Urteaga decidió a favor del Dr. Peña.

Años después (11-I-1937) la Facultad sesionó con el objeto de proveer los cursos que se encontraban servidos por los catedráticos interinos por carecer del Titular o por licencia del Principal, designando a quienes deberían regentarlas para el año 1937. Se nombró entonces catedrático interinos a los siguientes: Historia del Perú ( $1^{\circ}$ curso), Luis E. Valcárcel; Historia del Arte Peruano, Juan M. Peña Prado; e Historia de la Cultura (curso avanzado), Teodosio Cabada. Asimismo fue elegido catedrático Interino de Arqueología Americana y del Perú al Dr. Julio C. Tello con 17 votos contra Hildebrando Castro Pozo 1 voto. 


\section{El Concurso por el Titularato de la Cátedra}

En la sesión del 15 octubre de 1937, el Decano de entonces, Dr. Luis Miró Quesada, manifestó que de acuerdo con la reglamentación de los concursos, y habiéndose expresado ya los informes respectivos, se había convocado a los profesores de la Facultad para proceder a la elección de los catedráticos Titulares de Historia del Arte Peruano y de Psicología; y que conforme al artículo $7^{\circ}$ de esa misma reglamentación, y estando presente la señorita Rebeca Carrión Cachot, postulante a la cátedra de Historia del Arte Peruano, se la iba hacer pasar al salón con el objeto de que procediera a dar lectura a su programa. Manifestó también el Decano que había recibido noticia verbal del Doctor Villar Córdova, dándole a saber que el postulante a la cátedra de Psicología se encontraba fuera de Lima y que probablemente no podía venir sino dentro de algún tiempo. Consultó, además, a los catedráticos concurrentes, si se podía dar lectura a los programas de todos los postulantes o solo los informes; se acordó que se leyeran solamente los informes, en mérito de los cuales podía procederse a la elección de los candidatos.

A continuación ingresó a la sala de sesiones la Dra. Rebeca Carrión y de inmediato dio lectura a la exposición de su programa. Al terminar, el decano expresó a la Dra. Carrión el interés que había despertado la lectura de su exposición y que sus indicaciones serían tomadas en cuenta por los catedráticos en el momento de ocuparse del concurso de la cátedra de Historia del Arte Peruano. La Srta. Carrión se retiró del salón.

Luego se leyó el informe de la Comisión encargada de dictaminar los expedientes de los postulantes a la cátedra de Historia del Arte Peruano, manifestando el Decano que se tomarían en cuenta las indicaciones que en él se hacían, referentes a la mejor ubicación de la cátedra en el $4^{\circ}$ año del plan de estudios de la Facultad.

El Dr. Salinas Cossío pidió que se dejara constancia que "el programa de la Dra. Carrión no correspondía a las condiciones y motivos de la convocatoria a concurso por el amplio desarrollo que dicha postulante concede a la Arqueología en cuyo aspecto es monográfico". Dijo además que existiendo en la Facultad una cátedra de Arqueología, y tratándose de un concurso para proveer la cátedra de Historia del Arte Peruano, "se advierte que no hay proporción entre los temas de este y arqueología; pues a estos concede [la Dra. Carrión] 14 o 15 capítulos y a los primeros solo se les estudia en uno o dos capítulos".

En votación secreta se eligió al Dr. Juan Manuel Peña Prado catedrático Titular de Historia del Arte Peruano. El informe final fue el siguiente:

En cumplimiento de la designación de la Junta de catedráticos de esta Facultad, para dictaminar respecto a los programas presentados por los Dres. Juan Manuel Peña Prado y Rebeca Carrión Cachot, en el concurso para la provisión de la cátedra, hemos llegado a la siguiente conclusión:

Programa del Doctor Peña Prado: abarca los tres periodos históricos de nuestro país: aborigen, colonial y republicano, con una extensión para cada uno de ellos en armonía a su importancia relativa.

Con ánimo indudable de preparar a los alumnos, carentes de esos conocimientos, para la mejor comprensión del arte nacional, se incluye, innecesariamente, una parte dedicada a la arqueología peruana, así como otras que corresponden a la Historia del arte en general. Ese defecto debe y puede subsanarse acordando la Facultad que los alumnos, para matricularse en este curso, hayan antes aprobado las de Historia General y del Perú, Historia del Arte, Arqueología y Estética, a fin de que la cátedra se concrete al tópico particular que ha motivado su creación. 
Encontramos sí conveniente, el estudio, que este programa preconiza, de la historia del nacimiento y evolución de los estilos hispánicos, como imprescindible antecedente para el mejor entendimiento del arte en el Perú.

El programa evidentemente, no establece una división sistemática en épocas diferenciales de nuestra historia artística, ni contiene generalizaciones sobre la materia, pero creemos que ello no cabe efectuarse por ahora, teniendo en cuenta el estado embrionario de las investigaciones sobre este particular entre nosotros.

En cambio juzgando muy acertado el sistema que se propone y se ha venido llevando a cabo, de hacer el estudio mediante la experiencia de monografías sobre determinados monumentos y fases artísticas, concatenándolas cronológicamente, como lo realiza el concurrente. Todo esto, también en vista de la expresada deficiencia de trabajos y conocimientos sobre tan vasto y complejo tema y como el único medio, por el momento, de efectuar una labor encaminada a la investigación de seminarios, con el objeto de formar un verdadero curso de arte peruano. De esta manera se hace labor más efectiva que avanzando generalizaciones peligrosas, más que nada por prematuras.

Programa de la Dra. Rebeca Carrión: Comprende, asimismo, una visión de conjunto, organizada, igualmente en tres periodos, que revela conocimiento de la materia del concurso y, sobre todo, en lo que se refiere, en general, a la época prehispánica. A este respecto, dedica una extensión desproporcionada y casi exclusiva al estudio de la arqueología nacional, para cuya enseñanza existe una cátedra especial en nuestra Facultad. Por el contrario, concede muy reducido espacio a los periodos colonial y republicano, que consideramos constituyen los capítulos más importantes y copiosos en la historia del arte de nuestra patria.

Concluyendo, opinamos que debe aceptarse preferentemente el programa presentado por el Dr. Juan Manuel Peña Prado, habiéndonos permitido hacer algunas sugerencias sobre la ubicación de esta cátedra como curso exclusivamente doctoral y de investigación, porque ellas han informado nuestro criterio para la apreciación de los programas.

Nos es muy grato expresar señor Decano nuestras anteriores conclusiones.

Firmado:

Guillermo Salinas Cossío, Teodosio Cabada, José Valega.

Como vemos, la Dra. Rebeca Carrión no pudo acceder al titularato de la cátedra. Al año siguiente (31-III-1938) se realizó otra votación, pero esta vez para la cátedra interina de Arqueología Americana y del Perú. La votación fue así: Dr. Julio C. Tello 13 votos contra la Dra. Rebeca Carrión, 1 voto.

El 6 de diciembre de 1941 la Dirección de la Escuela de Verano de la Universidad de San Marcos, presidida por el Dr. Víctor Andrés Belaunde, envió un oficio al Rector para comunicarle los acuerdos tomados por la Junta Ejecutiva de la Escuela en sus sesiones de los días 13, 18 y 28 de noviembre y 3 de diciembre de aquel año con el fin de asegurar las labores de la Escuela para los meses de enero, febrero y marzo de 1942. El acuerdo principal era la creación de varios Departamentos, uno de ellos era el Departamento de Antropología Peruana, que tenía como Jefe al Dr. Julio C. Tello. El Departamento contenía los siguientes cursos:

Geografía del País de los Inkas: Límites del dominio territorial del Imperio. Topografía e hidrografía. Zoogeografía. Fitogeografía. Las regiones naturales. Recursos económicos explotados por los aborígenes antes de la conquista española. El curso estaría a cargo del Dr. Javier Pulgar Vidal 
Arqueología Preinkaica. Las Civilizaciones Andinas: Raza y civilización. Las culturas de la Primera Edad. Caracteres Pan-andinos. Las culturas de San Agustín, Chavín, Paracas, Pukara y Tiahuanaco. El curso estaría a cargo del Dr. Julio C. Tello.

Arqueología e Historia Inkaica: Caracteres generales de las civilizaciones de la Segunda Edad. Las culturas Chimú, Muchik, Huaylas, Nazca y Chanca. Las naciones que integraron el Imperio de los Inkas. Caracteres generales de la civilización inkaica. El curso estaría a cargo de la Dra. Rebeca Carrión Cachot y del Dr. Toribio Mejía Xespe.

Gobierno y Organización Social del Imperio de los Inkas: Dr. Hildebrando Castro Pozo.

La Dra. Carrión estaría dictando el curso de Arqueología e Historia Inkaica junto al Dr. Toribio Mejía Xespe, sin embargo, el Plan de Estudios cambiaría días después. El 9 de enero de 1942 el Rectorado emitió un documento basándose en lo dispuesto en una Resolución Rectoral, inciso $5^{\circ}$, el cual decía: "Los profesores y conferencistas serán designados por el Consejo Universitario". La anterior propuesta de los cursos y los profesores para la Escuela de Verano había sido elaborada por los directivos de la misma Escuela de Verano, pero según la Resolución que cita el documento del Rectorado, esa designación debía hacerla el Consejo Universitario, entonces, bajo esa premisa, los profesores y los cursos del Departamento de Antropología Peruana cambió y quedó así:

Geografía del País de los Incas: Ingeniero Juvenal Monge

Arqueología Preincaica e Incaica: Dr. Julio C. Tello.

Historia Incaica: Dr. Luis E. Valcárcel.

Gobierno y Organización Social del Imperio de los Incas: Dr. Roberto Mac-Lean y Estenós

Biología Andina: Dr. Alberto Hurtado.

No tenemos suficiente información para asegurar si la Dra. Carrión dictó el curso en el verano de 1942, lo que sí podemos asegurar es que cooperó en la Escuela en 1941.

El ejercicio de la arqueología, la lucha por el Titularato y la dirección del Instituto

Años después, en otra sesión (15-VI-1942), y bajo el decanato del Dr. Horacio Urteaga, el Dr. Tello manifestó que se proponía viajar al Valle de Urubamba con una brigada de arqueólogos para hacer estudios en dicha región. En ese entonces, Tello expresó que debiendo ausentarse al sur del país para continuar sus investigaciones arqueológicas, solicitaba licencia por 4 o 5 meses.

La Facultad, teniendo en cuenta la clase de trabajos que iban realizar, recomendó al Consejo Universitario para que se le abonara el sueldo de catedrático durante su ausencia. Ante esto, Tello se refirió “a la importancia que tenían las investigaciones arqueológicas para la Facultad de Letras, la que se haría cargo de la trascendencia de las mismas en lo que refería a la enseñanza de la Arqueología y a los trabajos de investigación que concierne realizar a los alumnos del curso. Aludió el interés que existe hoy, fuera del país, por conocer la historia de este continente y en especial la del Perú, y a su pensamiento con relación a los estudios de Arqueología en la Facultad. Creo que es pobre -dijo- la idea de que se tiene de ellos y que no se han colocado en su verdadero sitio; que hay cátedras como las de Fuentes Históricas, Historia de la Cultura, Historia de los Incas, Historia del Arte Peruano, Arqueología, Antropología y Biología que pueden estar unidos y coordinados sus programas; que el curso de Arqueología debe ser en la Facultad un curso avanzado, y para el que se requiere nociones de Ciencias Naturales, de Biología y Antropología; pero que para darle el desarrollo que le corresponde, no se cuenta en el país con personal preparado. Que el país necesita poner a salvo, con personal nacional, 
la riqueza arqueológica que posee, porque el extranjero que viene y trabaja lo hace para sus instituciones, y vemos así perderse nuestras riquezas. Manifestó haber recibido del Sr. Rockeffeller 2,000 dólares para realizar una expedición al Marañón y que como resultado de ella existen amontonados 40 cajones sin poderse exhibir el valioso material recogido. Que el mismo señor le dio 3,000 dólares para salvar de la destrucción el material de Paracas, accediendo a su pedido de ayuda. Que en 1941 visitó el señor Luna Iglesias el Museo a su cargo y que el interés que despertó en él estos estudios, lo determinó a obsequiarle un terreno con el objeto de que edificara un local adecuado, habiendo aceptado esa donación mientras viva, debiendo pasar a su fallecimiento ese local y cuanto encierra a la Universidad de San Marcos. Agregó que deseaba que supiera la Facultad de Letras que tenía ese terreno para hacer en él un Centro de Arte Peruano. Dijo que el Sr. Han, Secretario de una fundación, con capitales suecos y norteamericanos, que protege a instituciones culturales de este continente, le había dado dinero con este fin al Sr. Caso, quien le había consultado al Dr. Tello si podía encabezar una expedición arqueológica, para la que contaría con todo lo necesario. Acordada la expedición, la fundación en referencia ha enviado 6,000 dólares para los gastos y publicaciones, ofreciendo cubrir la suma de 10,000 dólares. Esta es -dijo- una oportunidad para que la Facultad pueda emprender un trabajo de organización y dirección, encaminado a desarrollar nuestras investigaciones con personal peruano, aprovechando el apoyo extranjero. Concluyó el Dr. Tello manifestando que la expedición se encontraba pronta a partir a los valles de los ríos Urubamba y Apurímac y que la integraba elemento peruano del Museo a su cargo y los alumnos de la Facultad de Letras".

Luego de la exposición, el Decano se refirió a la labor arqueológica del Dr. Tello y a la necesidad de coordinar los programas de los cursos, asunto que debía contemplarse en el Reglamento de la Facultad. Se refirió también a la postulación de varios jóvenes que reunían los requisitos exigidos para acompañar al Dr. Tello en la expedición.

Después de un cambio de ideas, la Junta de Catedráticos acordó encomendar al Dr. Tello la Comisión de realizar estudios arqueológicos en los valles de los ríos Urubamba y Apurímac con ocasión del viaje que iba a realizar con una brigada de arqueólogos a esa región del país.

Ahora, ante su ausencia, Tello recomendó a la consideración de la Facultad los servicios de la señorita Rebeca Carrión Cachot como Auxiliar para el catedrático que se nombrara en el curso de Arqueología. Sobre esto, en la siguiente sesión (25-VI-1942), se procedió a proveer la cátedra de Arqueología dejada por licencia del Dr. Tello. Se eligió catedrático Principal Interino de Arqueología al Dr. Horacio Urteaga. El Decano expresó que tomaría en cuenta la recomendación del Dr. Tello para utilizar los servicios de la Dra. Rebeca Carrión en la enseñanza del curso de Arqueología, e iba a utilizar los conocimientos de dicha señorita como Ayudante para las prácticas de los alumnos en los museos, los mismos que estaban relacionados con las lecciones teóricas del curso, y por cuyos servicios se abonarían a la señorita Carrión la suma de 250 soles mensuales.

En otra sesión (17-V-1946), el Dr. José Jiménez Borja, Decano de la Facultad de Letras, dijo que en su condición de Presidente de la Comisión de los Institutos de la Facultad, iba a dar cuenta de los acuerdos a que se había llegado luego de las diversas reuniones realizadas, y que ponía en conocimiento del Consejo de la Facultad los planes de Estudio de los Institutos de Literatura, Historia, Filosofía y Psicología, Antropología y Etnología, entre los que se consideraban cursos de reciente creación. Asimismo, propuso a la consideración del Consejo de la Facultad la elección de los profesores que debían servir dichos cursos; habiéndose consignado también en dichos cuadros los nombres de los catedráticos que ya pertenecían a la Facultad con el objetivo de presentar una relación completa de los cursos que integraban los Planes de los Institutos. 
El Consejo de la Facultad, después de un amplio debate sobre las necesidades de los cursos de nueva creación que integraban el Plan de Estudios, y teniendo en consideración los notorios méritos de los profesores propuestos para servir las cátedras, aprobó los planes de estudios de los Institutos de Literatura, Historia, Filosofía y Psicología, Antropología y Etnología, y, asimismo, eligió a los profesores que iban a dictar los cursos. En el caso del Instituto de Antropología, este fue el Plan de estudios:

Cursos del Colegio Universitario

Antropología General:

Paleontología Humana, 1 hora: Dr. Julio C. Tello.

Antropología Física, 2 horas: Dr. Pedro Weiss

Arqueología, 1 hora: Dra. Rebeca Carrión Cachot

Anatomía Comparada de los Vertebrados, 2 horas: Dr. Alfredo León Rendón

Antropología y Tipología, 1 hora: Dr. Alfredo León Rendón

Geografía del Perú, 3 horas: Dr. Javier Pulgar Vidal.

Cursos avanzado y de investigación:

Arqueología Americana:

Arqueología Norte y Centro Americana, 1 hora: Julio C. Tello

Arqueología sudamericana:

Arqueología del Norte y Centro Andino, 1 hora: Rebeca Carrión Cachot.

Arqueología del sur andino, 1 hora: Sr. Toribio Mejía Xespe

Arqueología Incaica, 2 horas: Dr. Alejandro Arancibia

Psicometría, 1 hora: Dr. Hans Hahn

Zoogeografía, aplicada al conocimiento de los animales aprovechados por el hombre en la Antigüedad, 1 hora: Dr. Johanes Wile

Fitogeografía, aplicada al conocimiento de las plantas aprovechadas por el hombre e la antigüedad, 1 hora: Dr. Augusto Weberbauer.

Paleopatología. 1 hora: Dr. Pedro Weiss.

Arte Antiguo Peruano, 1 hora. Rebeca Carrión Cachot.

De esta manera, como vemos, con la creación del Instituto de Antropología (que estaría bajo la dirección del Dr. Julio C. Tello) se crean también numerosas asignaturas de arqueología. Esto quiere decir que el Instituto también estaba brindando una formación de tipo arqueológica.

Más adelante (07-XI-1946), el Decano manifestó que un grupo de alumnos, del Centro de Investigaciones Históricas de la Facultad, había proyectado una gira de 10 días por la región del Centro para estudiar los archivos de Jauja y Huancayo según el plan recomendado por la Dra. Ella Dunbar Temple. Los alumnos solicitaban S/. 959.40. Igualmente, se acordó entregar S/.150.00 a los alumnos del curso 
de Arqueología para visitar Paramonga y otros lugares de interés arqueológico, esto estaría a cargo de la Dra. Rebeca Carrión Cachot.

Más adelante (16-V-1947) se ratificó a los siguientes profesores: Dra. Rebeca Carrión para Arqueología del Norte y Centro Andino y Arte Antiguo del Perú; Dr. Toribio Mejía Xespe para Arqueología del Sur Andino y Arqueología Incaica; Dr. Luis E. Valcárcel para Introducción a la Etnología; y Bachiller Jorge Muelle para Investigaciones Enológicas en el Perú (trabajos de campo y gabinete).

De otro lado, el Decano expresó que el Dr. Tello, director del Instituto de Antropología, le había enviado un cuadro con la nueva distribución de los cursos del Instituto: Arqueología Sudamericana General, a cargo del Dr. Tello; Arqueología del Norte y Centro Andino, a cargo de la Dra. Rebeca Carrión; Arqueología del Sur andino y Arqueología Incaica, a cargo del Dr. Toribio Mejía Xespe. Además, se aprobaron los siguientes Seminarios: Arqueología Peruana, a cargo del Dr. Tello; Arte Antiguo Peruano, a cargo de la Dra. Rebeca Carrión; y Antropología Física y un Asistente del Seminario de Arqueología Peruana.

En la sesión del 8 de julio de 1947, el Decano de la Facultad, Dr. José Jiménez Borja, puso en conocimiento a los catedráticos sobre el fallecimiento del Dr. Julio C. Tello. Ante ese hecho, la dirección del Instituto de Antropología recayó en la Dra. Rebeca Carrión Cachot. Como directora del Instituto, la Dra. Carrión propuso al Decano el nombramiento del Sr. Manuel Chávez Ballón como asistente del Seminario de Arqueología y al Dr. Julio C. Pretto para el curso de Antropología Física. Ambas propuestas fueron aceptadas.

En esa misma sesión el Decano expresó el problema que estaba acarreando la construcción de la futura Ciudad Universitaria, dijo que el Consejo Universitario urgía que la Facultad diera su propuesta sobre el Pabellón de Letras que iba a construirse en la nueva sede de la universidad. Dijo que la Junta de Catedráticos había decidido que en la futura Facultad se debía reproducir la actual arquitectura de los dos patios, además se nombraría una Comisión especial conformada por los directores de los Institutos y 3 delegados de los estudiantes para determinar las características definitivas de dicho edificio.

El Decano manifestó también que el Instituto de Arqueología había propuesto la contratación del eminente arqueólogo y profesor argentino Fernando Marques Miranda, Doctor Honoris Causa de la Facultad. Dicho contrato tendría una vigencia de 2 o 3 años, con el haber de S/. 1500 mensuales, corriendo el Rectorado con el pago de pasajes de ida y vuelta del profesor y toda su familia. El Dr. Marqués dictaría un curso de Arqueología General y otro de Arqueología Americana, ya que los cursos relacionados con Arqueología Peruana eran dictados por la Dra. Rebeca Carrión y el Dr. Mejía Xespe.

En la sesión del 9 de abril de 1948, el Consejo ratificó el nombramiento de los siguientes profesores de la categoría "B" del Instituto de Arqueología:

Dra. Rebeca Carrión Cachot de Arqueología del Norte y Centro Andino y Arte Antiguo del Perú.

Profesor Toribio Mejía Xespe de Arqueología del Sur Andino y Arqueología Incaica

Dr. Julio Pretto de Antropología Física.

Dr. Manuel Chávez Ballón, Asistente del curso de Arqueología Peruana.

El 5 de mayo 1949, la Junta eligió catedráticos Principales Interinos a los profesores del Instituto de Arqueología para las cátedras que carecían de Titular, o cuyo Titular gozaba de licencia o se encontraba ausente: 
Antropología Física: Pedro Weiss

Arqueología Americana: Pedro Villar Córdova

Arqueología Peruana (Pre incaica): Rebeca Carrión Cachot

Arqueología Peruana (incaica): Toribio Mejía Xespe

Seminario de Arqueología como asistente a don Luis F. Gálvez

Asistente del Seminario de Antropología al Dr. Julio C. Pretto

En junio de 1949 se dio cuenta de una solicitud de la Dra. Rebeca Carrión para ser catedrática Principal Titular de Arqueología Pre incaica. Al parecer no hubo respuesta positiva al pedido. La Dra. Carrión mantuvo su categoría de Principal Interina en sus cátedras.

En octubre, el Decano manifestó a la Junta que había recibido una carta del Dr. Luis E. Valcárcel, fechada en París, dando cuenta de su labor ante la Comisión de Expertos en Restauración de Monumentos Históricos y Artísticos y como observador ante la IV Conferencia General de la Unesco. Agregó que como Delegado de la Facultad ante el XXIX Congreso Internacional de Americanistas, realizado en Nueva York, el Dr. Valcárcel había efectuado una fructífera labor, así como el Dr. Jorge Muelle y la Dra. Rebeca Carrión, siendo esta ultima la que "abrió y aplicó por primera vez la técnica del carbono 14 a un fardo funerario de la cultura Paracas, de la que obtuvo como resultado una antigüedad aproximada de 3000 años" (Nava 1998: 5).

En otra sesión (29-III-1950) se procedió a elegir catedráticos Principales Interinos a los profesores del Instituto de Arqueología que carecían de Titular o cuyo Titular gozaba de licencia:

Antropología Física: Pedro Weiss

Arqueología Americana: Pedro Villar Córdova

Arqueología Peruana ( $1^{\circ}$ curso-época Pre incaica): Rebeca Carrión Cachot

Arqueología Peruana ( $2^{\circ}$ curso-época Incaica): Toribio Mejía Xespe

Asistente del Seminario de Antropología Física: Julio C. Pretto

Asistente del $1^{\circ}$ curso de Seminario de Arqueología: Bachiller Julio Espejo Núñez

Asistente del $2^{\circ}$ curso de Seminario de Arqueología: Dr. Luis F. Gálvez de Castro

Más adelante (19-IV-1951) fueron elegidos los siguientes catedráticos Interinos del Instituto de Arqueología:

Antropología Física: Pedro Weiss

Arqueología Americana: Pedro Villar Córdova

Arqueología Pre incaica: Rebeca Carrión Cachot

Arqueología Incaica: Toribio Mejía Xespe

Días después, (23-V-1951), el Decano manifestó que en la sesión pasada se había nombrado a los catedráticos del Instituto de Arqueología y que faltaba el nombramiento del personal auxiliar y administrativo. Agregó que la directora del Instituto había sugerido un cambio en las denominaciones de dicha plaza, así como el nombramiento de diferentes personas. 
Ante esa situación, el Secretario dio lectura al oficio de la Dra. Rebeca Carrión. Después de la intervención de algunos catedráticos, la Junta tomó el acuerdo de solicitar previamente del Instituto de Arqueología los motivos que habían determinado al Instituto la supresión en el presente año del Seminario de Arqueología, motivos que debían ser expuestos por dicho Instituto.

Meses después (20-VII), la Dra. Rebeca Carrión envía un nuevo oficio al decano de la Facultad, Dr. Aurelio Miró Quesada, sobre su promoción al título de Catedrática Principal Titular. En ese entonces, la doctora llevaba cerca de 6 años como profesora de Arqueología Peruana en la categoría de catedrática Principal Interina, y de acuerdo al Estatuto de entonces, ella reunía todos los requisitos establecidos para obtener el título de Catedrática Principal Titular. Por ejemplo, el artículo $440^{\circ}$ establecía, para acceder al titularato, "competencia notoria en la materia de la Cátedra, demostrada con trabajos de investigación o haber servido en el ejercicio de la docencia auxiliar o interina o del profesorado en cualquier instituto de enseñanza superior durante tres años cuando menos", y el artículo $451^{\circ}$, inciso $4^{\circ}$, establecía que la Facultad podía nombrar directamente Catedrático Principal Titular "a los catedráticos interinos que tuviesen por lo menos tres años consecutivos en el ejercicio de sus cátedras, siempre que hubiesen publicado o entregado a la Facultad para su publicación el programa razonado del curso, el texto del mismo o autorizado la publicación de sus lecciones o fueran autores de obras notables de índole universitaria".

Cumpliendo lo que establecía el Estatuto, la doctora agregó lo siguiente:

Deseo dejar constancia, con todo respeto, de que durante el tiempo que ejerzo la enseñanza universitaria, he puesto al servicio de ella mi experiencia arqueológica, mi entusiasmo por los altos principios pedagógicos de la Facultad que usted dignamente preside y un hondo espíritu de cooperación a todo lo que significa fomento de las inquietudes culturales de la Universidad. Esto último esta traducido en las periódicas Exposiciones Arqueológicas preparadas por mí para su utilización por el estudiantado; en la organización de cortas expediciones y exploraciones en las que han participado los alumnos del curso de Arqueología; en la organización de un Archivo de Slides y fotografías que se pasan por la pantalla; y en el fomento de trabajos de investigación por parte del alumnado.

Para entonces, la Dra. Carrión no solo llevaba 6 años de docencia en San Marcos, sino también 4 años dictando cátedra en la Universidad Católica, lo que hacía un total acumulativo de 10 años. En su oficio la doctora había tomado como referencia el año 1945 como el inicio de su carrera docente, cuando en realidad ella había iniciado la docencia universitaria en 1931 cuando dictó el curso libre de Arte Peruano Pre Colombino, como ya anotamos líneas arriba.

No había duda de la competencia de la Dra. Carrión en la ciencia arqueológica, ya sea en la cátedra, en el ejercicio de la profesión, o en las publicaciones. Por todo ello, merecía ser nombrada Catedrática Principal Titular. Sin embargo, no hubo respuesta ante el pedido, al menos no encontramos documentos que den una respuesta concreta, lo que sí es cierto es que la doctora permaneció con su categoría de Principal Interina. Por ejemplo, el 24 de marzo de 1953 se ratificaron catedráticos interinos porque los titulares estaban de licencia. Así, en el Instituto de Arqueología, se ratificaron a los Dres. Pedro Weiss, para Antropología Física; y Rebeca Carrión Cachot, para Arqueología Preincaica.

La crisis del Instituto de Arqueología y su reorganización

En la sesión del 11 de agosto de 1953 el Decano expuso la situación en que se encontraba el Instituto de Arqueología, manifestó que en los cursos de Antropología Física, Arqueología Pre Incaica y Seminario de Antropología, solo había un alumno matriculado. Además agregó que en el curso de Arqueología Americana, para la que no se había nombrado profesor, se habían matriculado diez 
alumnos y que estos no se habían inscrito en los otros cursos de Arqueología Incaica, Seminario de Arqueología Pre incaica y Seminario de Arqueología Incaica. Expresó que ante esta situación, y de conformidad con la Resolución Rectoral № 6296 (IV-1947), que establecía un mínimo de cinco alumnos matriculados para que un curso pueda dictarse, el Instituto no podía cumplir ese año con su labor docente. El Decano dijo que la Facultad debía abrir simultáneamente caminos positivos para el próximo año académico, con redistribución de cursos alicientes para los alumnos, facilidades prácticas, etc. Sobre esto, el Decano había cambiado ideas con la directora del Instituto, Dra. Rebeca Carrión, y con el Director del Instituto de Etnología, Luis E. Valcárcel.

Luego de un extenso cambio de opiniones, en que intervinieron los Dres. Luis Felipe Alarco, Ella Dunbar Temple, Alberto Tauro, Tamayo Vargas y Luis E. Valcárcel, sobre las mejores posibilidades para el mayor desarrollo de los estudios arqueológicos en la Facultad y el aprovechamiento, a favor de la enseñanza, del Museo Arqueológico de la Universidad, la Junta tomó el siguiente acuerdo:

La Facultad acuerda: $1^{\circ}$ no dictar en el presente año académico los cursos del Instituto de Arqueología para los que aún no se han nombrado profesores, ni aquellos que no tiene el número suficiente de alumnos matriculados, a fin de proceder a su reorganización. $2^{\circ}$ Fusionar los actuales Institutos de Etnología y Arqueología y encomendarles que, de acuerdo con la Comisión Pedagógica, proponga a la Facultad una redistribución de las materias en esas especialidades, o posibles cambios en los cursos para el próximo año académico. $3^{\circ}$ Encargar a la Comisión de Reglamento la preparación de un proyecto sobre títulos o certificados, independientes de los grados académicos de Bachiller y Doctor, que se entregarán a los alumnos que comprueben haber aprobado satisfactoriamente los cursos teóricos y los trabajos de campo o pruebas prácticas correspondiente a esa especialidad; y $4^{\circ}$ Reiterar al Rector y al Consejo Universitario, de acuerdo con el oficio del Decanato de fecha 2 de mayo último, la solicitud de que se establezca entre la Facultad de Letras y el Museo Arqueológico de la Universidad el mismo régimen existente entre la Facultad de Ciencias y el Museo de Historia Natural.

Esta medida trajo como consecuencia la fusión de los Institutos de Arqueología y Etnología, recayendo la dirección general en el Dr. Luis E. Valcárcel.

Más adelante (05-IV-1954), y a pedido del Dr. Luis E. Valcárcel, director del Instituto de Arqueología y Etnología, fueron elegidos catedráticos Principales Interinos los siguientes profesores: Dra. Rebeca Carrión Cachot para Arqueología Incaica; Pedro Weiss para Antropología Física, y al R.P. Pedro Villar Córdova catedrático Auxiliar de Arqueología Americana.

En 1955 la Dra. Rebeca Carrión se casaría con el Dr. Rafael Girard, americanista y etnólogo francés. La Dra. Carrión aún mantendría relación con San Marcos a través de sus cátedras y la dirección del Museo de Arqueología durante todo el año de 1955. Sin embargo, esto terminaría en la sesión del 13 de enero de 1956, allí, la Junta de Catedráticos accedió dar licencia por un mes a la Dra. Carrión.

No veríamos a la doctora Carrión desde esas fechas porque tomaría la decisión de viajar a Guatemala, allí continuaría sus investigaciones arqueológicas hasta su fallecimiento (03-IV-1960). Su decisión de residir fuera del Perú quizá tuvo que ver con el difícil contexto que le tocó vivir en la Universidad. Por esos años, el enfrentamiento y las críticas entre los profesores eran evidentes. Siempre ha existido la confrontación generacional entre los catedráticos de San Marcos (y de otras universidades por supuesto). La doctora Carrión no fue ajena a ello. En San Marcos le hacían la vida imposible, y entre otras razones, mientras a los jóvenes catedráticos que recién se iniciaban en la docencia se les 
otorgaba el titularato de la cátedra, a la doctora, quien tenía varios años de docencia en la universidad, se le negaba el titularato de la misma. Sobre esto, Luis Alberto Sánchez nos dice lo siguiente:

Al ocurrir el fallecimiento de Tello, [Rebeca Carrión] ganó la cátedra de Arqueología. Mucho más tarde la encontré en Chile. Rebeca conservaba su aire infantil. Me anunció que se iba a casar, que radicaría en Guatemala, que en Lima le hacían la existencia imposible. Lamentablemente, Raúl Porras, siempre tan apasionado, formaba parte del grupo que hostilizaba a Rebeca. Esta partió a Guatemala, se casó con el arqueólogo y teósofo francés Girard, y al poco tiempo murió (1969: I, 234-235).

\section{Consideraciones finales}

El presente texto ha tenido por función dar a conocer la presencia académica de Rebeca Carrión Cachot en la universidad de San Marcos. La doctora Carrión es un claro ejemplo de los vientos nuevos y viejos que soplaron en la universidad después de la reforma de 1919, son los años 20 del siglo XX en los que las mujeres iban conquistando un lugar en la vida pública, no sin enfrentarse a los valores de la época que relegaban a la mujer al ambiente doméstico.

Cuando en 1917 ingresó a la universidad la doctora Carrión fue apenas una de tres mujeres matriculadas en la Facultad de Letras junto a un centenar de varones.

Proveniente de una familia de clase media empobrecida, desde su primer año en la universidad Rebeca Carrión demostró ser una mujer inteligente, lo que le permitió sortear las dificultades económicas accediendo a becas y la exoneración de pagos. Pese a las dificultades económicas logró culminar con éxito sus estudios universitarios y obtener el grado de doctor en 1931.

Desde este momento y por cerca de 25 años la doctora Carrión dedicaría su vida a la universidad y al estudio de la arqueología, que la apasionaba. Fue justamente la primera mujer arqueóloga, una especialidad tradicionalmente asociada a los hombres, y fue además la primera mujer en dictar una cátedra universitaria en 1931, cuando empezó el dictado del curso libre de Arte Precolombino, y tras un largo paréntesis volvió a dictar en 1945 sus asignaturas de arqueología hasta 1955 en que dejó la dirección del Museo de Arqueología y la cátedra universitaria.

Su pasión por la arqueología la convertiría en colega y amiga cercana de Julio C. Tello, con quien trabajó y compartió la docencia y a quien, tras su muerte en 1947, sucede en la dirección del Instituto de Arqueología, cargo que ocupó hasta la fusión de este con el Instituto de Etnología en 1953.

Sus éxitos sin embargo se dan en medio de un ambiente poco amigable y hasta hostil, por razones poco claras se le niega reiteradamente el Titularado principal de la cátedra de arqueología pese a tener la capacidad y la experiencia necesarias, tras reiteradas solicitudes se mantiene en su calidad de Catedrática Principal Interina, hasta que abandonó la docencia en 1956, quizá resintiendo mucho el no ser valorada.

Se casó en 1955 y dejó el país. El último testimonio que tenemos de ella es un recuerdo de Luis A. Sánchez, quien encontrándola en Chile, le manifestó su cansancio por la hostilidad que se le mostraba en la universidad. Radicó en Guatemala, donde se dedicó todavía a la arqueología y muere poco después en 1960, lejos de su patria y de su universidad, la que la vio crecer y a la que dedicó los mejores años de su vida.

Con sus defectos y virtudes, errores y aciertos, la Dra. Rebeca Carrión es una ilustre sanmarquina que debe ser revalorada en nuestra universidad, San Marcos. 


\section{Documentos}

ARCHIVO HISTÓRICO DE SAN MARCOS. Documentos sin clasificar, correspondencias, Expedientes, solicitudes, actas, 1917-1958.

\section{BibliografíA}

MATICORENA, Miguel

2001 “Mujeres celebres de la Universidad de San Marcos". Revista del Archivo General de la Nación, $\mathrm{N}^{\circ}$ 22: 3-8. Lima.

NAVA, Ernesto

1998 “La Mujer Peruana, una Elite en el Mundo: Rebeca Carrión Cachot”. Boletín del Museo de Arqueología y Antropología de la Universidad Nacional Mayor de San Marcos. Año 1, N 3: 4-5. Lima.

NÚÑEZ, Efraín

2015 "La Escuela Académico-Profesional de Arqueología de la Universidad de San Marcos. Antecedentes institucionales (1921-1946)”. Historia y Región, N³ 179-190. Lima.

SÁNCHEZ, Luis A.

1983 El Perú: nuevo retrato de un país adolescente. Lima: Mosca azul Editores. 2º edición.

1969 Testimonio personal. Memorias de un peruano del siglo XX. Lima. Tomo I.

TAURO DEL PINO, Alberto

2001 Enciclopedia Ilustrada del Perú. Tomo 4. Lima: Ediciones Peisa.

VALCÁRCEL, Carlos D.

1967 La Facultad de Letras y Ciencias Humanas (1919-1966). Lima. 